\title{
On-line Colorimetry System by Telescopic Spectrophotometer*
}

\section{Introduction}

In steel industries, the surface colorimetry of steel sheets, especially of colored galvanized sheets, is important for quality control. For the measurement, "on-line" or "off-line" visual inspection, or "off-line" instrumental inspection is usually used.

For the strong needs of automatic inspection, a new on-line inspection system has been developed. It is now being applied to the continuous inspection of color difference in a production line of colored galvanized sheets.

\section{Features of This System}

The instrument is shown by Photo. 1.

This spectrophotometer has a number of features for on-line use as follows:

(1) High Illuminant Light-sources

Two halogen lamps illuminate a travelling object with the intensity of more than $10^{5} \mathrm{~lx}$, so that the stray light noise is negligible.

(2) High Speed Signal Processing

The signal processing speed of the system is high enough so that the spectral reflective property of a travelling object is measured continuously and precisely. After the reflected light from the object is dispersed by a grating, its spectrum is imaged on the surface of a photodiode array. The optical spectrum extends from 400 to $700 \mathrm{~nm}$. The array consists of 31 diodes of the same size and the center-to-center spacing of the adjacent diodes is equivalent to $10 \mathrm{~nm}$ on the image of the spectrum. For signal enhancement, the spectrum signals in the 31 diodes are accumulated in parallel for a certain time and then electrically scanned. The scanned signal is processed by a 16 -bit microcomputer.

(3) Stable Measurement with High Accuracy

This system always monitors the fluctuations of light-source intensities and detector sensitivities so that stable measurement is achieved with high accuracy.

(4) Remote Inspection

Because of remote inspection, this system is available in almost any production line. Table 1 shows the specifications of this system.

\section{Results of On-line Tests}

On-line performance tests were tried in a production line of colored galvanized sheets in the Chiba
Works. The tests confirmed that the color difference, $\Delta E$, measured by on-line tests with this spectrophotometer coincided within \pm 0.1 with those measured by off-line sampling tests with the same instrument. The difference of \pm 0.1 is caused by two reasons:

(1) The installation in the offline tests is not exactly the same as that in the on-line tests.

(2) The on-line tests make measurement over an extended area, whereas the off-line tests make measurement only at a point.

The accuracy of measurement of this system is good enough for online use. For the improvement of accuracy, it is necessary to add a temperature control system.

The color differences of the sheet from its standard color were successfully measured over the whole length of a coil by using this system in the production line. On-line automatic color inspection will be also possible by this system in production lines of other kinds of steel sheets, such as galvanized sheets, pickled sheets. As a result, it is resultantly expected that the color difference will be controlled in the production line with this system.

Table 1. Equipment specifications of the system.

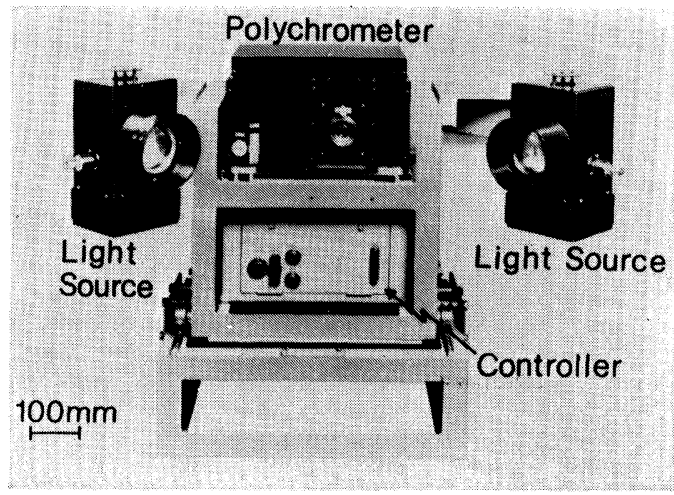

Photo. 1. Apparatus for the on-line colorspectrophotometry.

\begin{tabular}{|c|c|}
\hline Device & Specification \\
\hline Light source & Halogen lamp: $650 \mathrm{~W} \times 2$ \\
\hline Detecting unit & $\begin{array}{l}\text { Slit, Lenses, Grating, Mirror, } \\
\text { Photodiode array of } 31 \text { channels }\end{array}$ \\
\hline Amplifier unit & $\begin{array}{l}\text { Main amplifier, Lamp monitor } \\
\text { A/D converter: } 12 \text { bits }\end{array}$ \\
\hline Interface box & $\begin{array}{l}\Delta E \text { setting: Digital switch (Max. 9.99) } \\
\text { Control switch: } 3 \text { modes }\end{array}$ \\
\hline $\begin{array}{l}\text { Micro computer } \\
\text { system }\end{array}$ & $\begin{array}{ll}\text { Processor: } & \text { i8088, i8087 } \\
\text { Memory: } & \text { ROM 2KB, RAM 256KB } \\
& \text { Mini floppy disk 300KB }\end{array}$ \\
\hline Output unit & Printer, Pen recorder \\
\hline
\end{tabular}

* For further information, write to Engineering Division, Kawasaki Steel Corporation, 2-2-3, Uchisaiwai-cho, Chiyoda-ku, Tokyo 100. (C) 1985 ISIJ 